\title{
Muscular and neuromotor control and learning in the athletic horse.
}

\section{McGowan, Catherine Marie}

2017

McGowan , C M \& Hyytiäinen , H K 2017 , ' Muscular and neuromotor control and learning in pÿthe athletic horse. ' , Comparative Exercise Physiology , vol. 13 , no. 3 , pp. 185194 . https://doi.org/10.3920/CE

http://hdl.handle.net/10138/231629

https://doi.org/10.3920/CEP170001

cc_by_nc_sa

publishedVersion

Downloaded from Helda, University of Helsinki institutional repository.

This is an electronic reprint of the original article.

This reprint may differ from the original in pagination and typographic detail.

Please cite the original version. 


\title{
Muscular and neuromotor control and learning in the athletic horse
}

\author{
C.M. McGowan ${ }^{1 *}$ and H.K. Hyytiäinen ${ }^{2}$ \\ ${ }^{1}$ Institute of Veterinary Science, Faculty of Health and Life Sciences, University of Liverpool, Leahurst, CH64 7TE, United Kingdom; \\ ${ }^{2}$ Department of Equine and Small Animal Medicine, Faculty of Veterinary Medicine, University of Helsinki, P.O. Box 57, 00014 Helsinki, \\ Finland; c.m.mcgowan@liverpool.ac.uk
}

Received: 31 December 2016 / Accepted: 20 February 2017

○ 2017 Wageningen Academic Publishers

OPEN ACCESS (C) $\underset{\mathrm{BY}}{\mathrm{NC} \text { () }}$

REVIEW ARTICLE

\begin{abstract}
Athletic performance or the kinematics of locomotion is ultimately the result of the actions of muscles. Muscular actions differ depending on the muscle group involved with anatomical and functional properties depending on the primary roles of the muscle; from stabilisation to powering locomotion. The functional (contractile and metabolic) properties of a muscle are determined by its fibre type or relative fibre type proportions in the muscle. The actions of muscle require the coordination of the nervous system with muscle contraction to produce movement or resist movement to avoid unwanted motion and tissue damage. The coordination of muscular action with the nervous system is termed neuromotor control and it requires precise proprioceptive input from the periphery, processing and input from the central nervous system (including learned or trained movements) and involves timing of muscle recruitment as well as muscle contraction. Training of muscles involves training for strength (or force generation) and stamina with measureable physiological changes with training including increased fibre size, alterations in fibre type, alterations in glycogen concentrations and lactate transport and alterations in mitochondrial and capillary density. As well as standard athletic training, skills training can make the difference in athletic performance and injury prevention in the equine athlete. This involves training of neuromotor control; training motor skills by motor relearning and conditional learning. Practical specific training techniques can be used in injury prevention, rehabilitation post injury and maintenance of the athlete. In this review we will focus on the thoracolumbar and hindlimb areas of the horse and review the importance of muscular control of locomotion, neuromotor control, the physiological effects of training and practical ways to maximise performance potential by specific physiotherapy skills training.
\end{abstract}

Keywords: fibre type, muscle, motor skills, strength, stamina, motor learning

\section{Introduction}

The equine athlete successfully performs over a wide range of speeds and distances while carrying the weight of a rider. While elite human sprinters can average $37 \mathrm{kph}$ over 100 metres, a Thoroughbred flat racehorse can average 60 kph over 1,200 metres (Hodgson and Foreman, 2014). In equivalent $100 \mathrm{~km}$ races, leading human ultramarathon runners can average $14 \mathrm{kph}$ (Knechtle et al., 2012), while a recent welfare initiative from the United Arab Emirates (Boudheib initiative) capped the average speed of horses at $20 \mathrm{kph}$ over the same distance (Bin Zayed Al Nahyan, 2016).
There are a number of factors that contribute to the successful athletic performance of horses, including biomechanics and economy of locomotion, anaerobic capacity as well as aerobic capacity - the delivery, transport and utilisation of oxygen to create energy to power muscular performance (Hodgson and McGowan, 2014). Central to athletic performance are the actions of muscles. In this review we will focus on the importance of muscle control of locomotion, especially in the thoracolumbar and hindlimb areas of the horse. In particular, we will review the interplay between the nervous system and muscle to provide neuromotor control, important in injury prevention, the 
physiological effects of training muscle and practical ways to maximise performance potential by specific physiotherapy skills training.

\section{Muscular control of locomotion}

Locomotion in the athletic horse is powered by muscles and their ability to generate force (strength) and power (force over time or the product of the force and velocity of muscle contraction), where force generation is a product of muscle size or cross-sectional area and architecture, in particular fascicle length (Crook et al., 2008, 2010). Both force and velocity of shortening are also dictated by the contractile properties of the muscle fibres. Type II (fast twitch) muscle fibres have both a greater cross sectional area and faster velocity of shortening than Type I (slow twitch) muscle fibres (Rivero and Piercy, 2008).

The horse has a larger muscle mass than many other species, including meat producing animals (53\% of its body mass compared with $30-40 \%$ in meat producing animals) (Gunn, 1987). The Thoroughbred horse has also been shown to have a greater proportion of muscle in its hind limbs than non-athletic breeds of horses, associated with its role in powering exercise (Gunn, 1987). The biomechanical function of muscles can be determined from knowledge of fascicle size, length and orientation as well as the direction of force compared to the movement of associated joints. Moment arm is defined as 'the perpendicular distance between the axis of rotation of the joint and the force' (Neuman, 2010). Quarterhorses have been shown to have greater cross sectional area of muscle and longer fascicle lengths allowing their muscles to have greater isometric force production than Arabians (Crook et al., 2008); while Arabians generally had shorter moment arms and higher muscle fascicle length to moment arm ratios for their muscles (Crook et al., 2010). For a similar change in joint angle, the Arab muscle fibres undergo a proportionally smaller length change but due to this being optimal in the force-velocity curve, have a greater force potential. These findings support that Quarterhorse muscles favour maximal power output and Arabian horse muscles have a greater economy of locomotion (Crook et al., 2010).

As well as breed (and associated muscle size and architecture) supporting different types of locomotion as shown by the Thoroughbred, Arabian and Quarterhorse above, muscles within the same animal can also have different functions. Muscles can be generally divided into three main functions: (1) stabilisation, e.g. associated with joint stabilisation or core (postural) ability; (2) long-lasting and repetitive functions like respiration and low intensity locomotion; and (3) fast and generally powerful functions such as jumping, intense exercise (Schiaffino and Reggiani, 2011). Their ability to perform these roles is generally reflected in the main fibre type proportions of these muscles. Muscles can be divided in to slow (Type I) and fast twitch, and fast twitch into fast twitch highly oxidative (Type IIA or 2A) and Type II low oxidative/glycolytic (Type IIB or $2 \mathrm{X}$ ), where the differences in nomenclature refer to differences in identification of fibre type; Type I, IIA and IIB from histochemistry techniques and 1, 2A and $2 \mathrm{~B}$ from myosin heavy chain (MHC) isoforms (Valberg, 2014).

The functional differences in the different fibre types are related to fibre size or cross sectional area, and the power they can produce, a function of force over time, which is greater with a higher velocity of shortening. Fast twitch muscle fibres have both greater size and velocities of shortening so are the predominant in power generating muscles of locomotion. The difference in velocity of shortening between Type IIB (2X) fibres in horses is ten times greater that of Type I fibres, compared to only three to four fold difference in smaller animals (rabbits, rats) (Rome et al., 1990). Interestingly though, the difference was not an increase velocity of shortening in the Type IIB (2X) fibres, rather a decrease in Type I fibres, likely due to a lower energetic cost of locomotion in horses compared to small mammals (Rome et al., 1990).

As well as the speed of contraction, the resistance to fatigue and metabolic capacity is determined by muscle fibre type, with highly oxidative fibres (Type I and Type IIA/2A) being much more resistant to fatigue due to the presence of a greater number of mitochondria, lipid and capillaries; while Type IIB/2X muscle fibres have higher glycogen stores (Valberg, 2014). Fatigue resistant fibres are predominant in muscles required for low-level repetitive activities and postural stabilisation.

The fibre types of major muscles of the equine back and hindlimbs have been extensively studied, and recent research has included the fibre type of muscles that perform very different roles from the $\mathrm{m}$. diaphragm and $\mathrm{m}$. multifidii to the major muscles of locomotion, the mm. longissimus, middle gluteal and biceps femoris (Hyytiäinen et al., 2014; Kawai et al., 2009). The studies confirmed previous research findings demonstrating that the major hindlimb muscles $\mathrm{mm}$. gluteus medius and longissimus dorsi had a very high fast twitch fibre proportion; 85-90\% fast twitch Type 2X and 2A fibres. Muscles with dual roles of stabilisation and locomotion, such as $\mathrm{mm}$. psoas major and sacrocaudalis dorsalis lateralis, had $60-70 \%$ fast twitch fibres, while other locomotory muscles, such as mm. iliocostalis and biceps femoris, fell somewhere in between (Hyytiäinen et al., 2014; Kawai et al., 2009). There were some differences between the relative proportions of Type $2 \mathrm{~A}$ and $2 \mathrm{X}$ fibres, with one study using Thoroughbreds following prolonged training and relatively deep samples of muscles (mid-section of muscle) having greater Type 2A than $2 \mathrm{X}$ proportions (Kawai et al., 2009). While less well trained Arabians and Quarterhorses and muscles taken from a maximum of $5 \mathrm{~cm}$ 
depth had greater proportions of Type $2 \mathrm{X}$ than $2 \mathrm{~A}$ in their locomotory muscles, although this was more pronounced in the Quarterhorses (Hyytiäinen et al., 2014).

The fibre type proportions of the deep epaxial muscles of the equine back supported earlier work based on dissections and muscle fascicle orientation work that indicated $\mathrm{mm}$. mulifidii were core stabilising muscles (Stubbs et al., 2006). The mm. mulifidii in the horse were shown to be similarly morphologically orientated and thus functioning in a comparable way to that in man with the $\mathrm{mm}$. sacrocaudalis dorsalis lateralis and medialis continuing the function of the mm. mulifidii in the caudal spine (Stubbs et al., 2006). These muscles along with $\mathrm{m}$. psoas minor had 44-63\% fast twitch fibres, with most mm. mulifidii fascicles having around 50\% fast twitch fibres, indicating a dual postural stabilisation and locomotory role. Other muscles showed an even lower proportion of fast twitch fibres, indicating functions, such as stabilisation (such as the m. sacrocaudalis dorsalis medialis; $16 \%$ ) or repetitive muscular activity associated with respiration ( $\mathrm{mm}$. diaphragm; 28\%) (Hyytiäinen et al., 2014). Although the $m$. sacrocaudalis dorsalis lateralis had a $60 \%$ fast twitch fibre type proportion, there were $45 \%$ Type $2 \mathrm{~A}$ and only $13 \% 2 \mathrm{X}$ proportions indicating more fatigue resistance, supportive of its biomechanical function as an extension of mm. multifidii and a postural stabilising muscle (Hyytiäinen et al., 2014; Stubbs et al., 2006).

\section{Neuromotor control}

Stability and control of movement is highly dependent on the contribution of the muscular system, and not just the strength of the musculature, but the central nervous system's timing and control of muscle recruitment, called 'neuromotor control' (Hodges, 2004). In order to provide resistance to movement for a given joint, there is coordination between active elements (muscles) of the joint with the control system (the central nervous system), as well as the passive structures (such as ligaments, tendons, joint capsules and skeletal elements) (Panjabi, 1992a,b). The central nervous system receives sensory, proprioceptive input from the periphery including vestibular, visual and nervous input, and also input from changes in length, tension and rates of change in structures including tendons and muscles via their golgi tendon organs and motor end plates (Van Dieën and Kingma, 2013). It uses this input to control timing of muscle recruitment to provide effective control during locomotion and movements and to prevent excessive movement about a joint that could lead to tissue overload and injury (Hodges et al., 2013). Neuromotor control, therefore, provides a stabilising 'core' for maintaining joints in their appropriate position through their range of motion during locomotion and other perturbations. This position is called the 'neutral zone' of the joint (Panjabi, 1992a,b) where loss of this stabilising core (functional instability) results in movement beyond the neutral zone of a joint and predisposes that joint or its surrounding structures to degeneration or more acute injury (Goff et al., 2008).

Neuromotor control in the lumbo-pelvic region during movement and the reactions in the system to pain and injury are important areas of research in the prevention and management of back and pelvic pain in humans and horses (Hodges et al., 2013; Stubbs et al., 2010). As mentioned above, an important muscle group for neuromotor control in the thoracolumbar region are the $\mathrm{mm}$. multifidii with both in vivo and in vitro evidence demonstrating the ability of the multifidus muscle to have an important stabilising role for intervertebral motion (Hodges et al., 2013). In the presence of low back pain, the strategies used by the central nervous system to control trunk muscles may be altered resulting in less efficient muscle recruitment strategies (Hodges, 2001). Human patients with back pain display delayed activation of the musculature, especially of the deep, core muscles of the spine and trunk, depriving the painful and injured spinal segments of timely support (Hodges and Richardson 1996, 1999; Macdonald et al., 2009). Morphological changes, especially reduced crosssectional area, have been shown in the mm. mulifidii in association with low back pain in people and associated with pathological lesions in horses (Hides et al., 1996; Stubbs et al., 2010). What is notable is that there is not an automatic reversal of the dysfunction of mm. multifidii despite apparent recovery or resolution of pain following an episode of acute back pain (Hides et al., 1996).

Knowledge gained from this research related to the changes in neuromotor control that occur with back pain have translated to the development of rehabilitation strategies for the lumbo-pelvic muscles in back pain patients (Hodges et al., 2013; MacDonald et al., 2006) and also in horses (Stubbs et al., 2011). Strategies include motor relearning strategies that focus on the deep core muscles of the trunk and back, as well as combined movements to optimise motor control for stability of the spine during movement (Grenier and McGill, 2007; Hides et al., 2001, O’Sullivan et al., 1997; Stubbs et al., 2011). Such functional retraining exercises also involve training of the motor cortex (the controller in neuromotor control) where perturbations are predicted or anticipated and can be learned, often termed 'feed-forward' (Reeves et al., 2013).

\section{Physiological effects of training muscles}

As well as intrinsic ability determined by muscle structure and metabolic properties, as mentioned above, muscle function can be improved by training. This can be divided into relatively non-specific training associated with improvements in strength, speed, acceleration and resistance to fatigue (stamina). There is also more specific training which focuses on individual muscles 
and combined movements in order to improve skill and develop neuromotor control to reduce the risk of injury. The following section will focus on non-specific training.

\section{Strength, speed and acceleration training}

Improvements in strength, or force generation, are primarily a function of increases in muscle size or hypertrophy. Training, especially high intensity training, results in an increase in muscle fibre area conferring improved muscle strength and this has been demonstrated in many equine training studies in both endurance and racing horses (Rivero and Piercy, 2008). Even in intense training in horses muscle hypertrophy is not only from increased large type IIB (IIX) muscle fibres, but rather an increase in size of all muscle fibres. In one study where racehorses were trained using high intensity $(100 \%-110 \%$ maximal oxygen uptake $\left.\left[\mathrm{VO}_{2 \max }\right]\right)$ interval training on a treadmill for 32 weeks, there was significant hypertrophy of all fibres (I, IIA, IIB) with a 20-30\% increase in area (Tyler et al., 1998). Even greater increases in fibre area of all three fibre types (40$52 \%$ ) were seen in Arabians trained at $80 \% \mathrm{VO}_{2 \max }$ for up to $20 \mathrm{~km}$ daily over 12 weeks (D'Angelis et al., 2005). Other studies have demonstrated increased muscle fibre area in dressage (10-15\%) and show jumping (23\% increase in Type IIA fibres only) training programmes, although this increase was less than those horses that were exercised intensely, at $80 \% \mathrm{VO}_{2 \max }$ or greater (Rivero, 2007).

Increases in muscle strength occur relatively slowly with maximal changes evident by 12-16 weeks of training, and no significant changes seen in the first 7 weeks (D'Angelis et al., 2005; Tyler et al., 1998). Despite increased fibre size, there are limited changes in the basic fibre types (Type I and II) with training, even very high intensity training, with changes occurring within Type II fibres, not between Type I and II fibre types (see the stamina section below).

Speed and acceleration are a function of having a high anaerobic capacity and the availability of substrate for energy production that can be used rapidly at the onset of exercise (anaerobically) as well as a fast velocity of shortening (fast twitch muscle fibres). Training affects primarily substrate availability and several studies have shown increased resting muscle glycogen concentration with both endurance and high intensity training following as little as 10 days training (Geor et al., 1999; McGowan et al., 2002; Serrano et al., 2000). Highly trained horses have resting muscle glycogen concentrations similar to glycogen loaded humans of over $620 \mathrm{mmol} / \mathrm{kg}$ muscle dry weight (from only $520 \mathrm{mmol} / \mathrm{kg}$ muscle dry weight in the untrained state) (McGowan et al., 2002). Following 32 weeks of intense interval training $\left(100 \% \mathrm{VO}_{2 \max }\right)$ the rate of muscle glycogen utilisation per second was lower (1.32 $\mathrm{mmol} / \mathrm{s}$ in week 1 to $0.58 \mathrm{mmol} / \mathrm{s}$ in week 32), despite a much longer run time (148\%) when horses were exercised to fatigue at the same speed. This implies that the same exercise intensity was supported by a higher proportion of energy available from aerobic energy sources, facilitating glycogen sparing as well as improved performance following training (McGowan et al., 2002).

Although muscle glycogen concentration appears to increase rapidly with training, the duration of exercise within a training programme affects its increase, with longer duration of exercise (and more glycogen depletion) eliciting a greater increase in muscle glycogen concentration (Gansen et al., 1999). Two exercise programmes of 5 weeks duration were compared and showed that exercise of low intensity (velocities producing lactates of 1.5 or 2.5 $\mathrm{mmol} / \mathrm{l}$ ) and long duration (45 $\mathrm{min}$ ) was more effective in increasing muscle glycogen concentration than exercise of moderate intensity (velocity producing lactate of $4 \mathrm{mmol} / \mathrm{l}$ or approximately $\left.80 \% \mathrm{VO}_{2 \max }\right)$ and moderate $(25 \mathrm{~min})$ duration (Gansen et al., 1999).

It is important to note that the increases in resting muscle glycogen concentration observed following training in these studies was independent of baseline diet, and that glycogen loading using high carbohydrate diets does not increase glycogen resynthesis in the horse and can induce dangerous hind gut acidosis (Davie et al., 1994).

As well as improvements in substrate availability, training results in increased buffering capacity of muscle and increased lactate transport. Following exercise to fatigue at a constant speed, 32 weeks of training resulted in higher blood but not muscle lactate concentrations (McGowan et al., 2002). This supports the concept of improved lactate transport out of muscle and its uptake in red blood cells by monocarboxylate transporters (Koho et al., 2006).

\section{Resistance to fatigue (stamina)}

Resistance to fatigue (increased stamina) is a function of overall aerobic capacity, measured as $\mathrm{VO}_{2 \max }$ in the whole athlete. Improvements in $\mathrm{VO}_{2 \max }$ are related primarily to improved capacity of components of the pathway of oxygen - the delivery, transport and utilisation of oxygen to be ultimately used for production of energy within the muscle mitochondria (Hodgson and McGowan, 2014). Improvements in $\mathrm{VO}_{2 \max }$ with training confer better performance and faster recovery and are related to many factors including increased pulmonary and cardiovascular function and increased red cell volume (and haemoglobin concentration) (Hodgson and McGowan, 2014). Muscle adaptations with training related to improved $\mathrm{VO}_{2 \max }$ include increased capillary density, aerobic enzyme activity and mitochondrial volume in the working muscles as well as increased oxidative capacity of fast twitch muscle fibres with increased Type IIA/2A fibres relative to Type IIB/IIX (Valberg, 2014). 
Increased capillary density has been shown as a result of both endurance and high intensity training and is associated with improved blood supply to the exercising muscle and improved oxygen delivery (Serrano et al., 2000; Tyler et al., 1998). Despite theoretical concerns of a decline in aerobic capacity associated with increased fibre size, research studies have shown an overall decreased diffusional index in all fibre types, despite increased fibre size, with an overall improvement of aerobic capacity even in very intense training (Tyler et al., 1998).

Training also induces increased activities of muscle enzymes associated with aerobic energy production including citrate synthase and hydroxyacyl dehydrogenase, markers of the tricarboxylic acid cycle and beta hydroxylation of fatty acids respectively (Rivero and Piercy, 2008; Valberg, 2014). Interestingly, no change in lactate dehydrogenase, an enzyme involved in glycolytic/anaerobic pathways was seen over 32 weeks of training (McGowan et al., 2002) showing the predominate enzymatic changes with training are aerobic.

Alongside the increases in enzyme activities were increases in mitochondrial volume in both Type I (7.29 to $12.80 \%)$ and II muscle fibres (3.04 to 8.41\%) following 32 weeks of high intensity training (Tyler et al., 1998). In the same study, mitochondrial volume was shown to be correlated with both performance (run time; $\mathrm{R}=0.71$ ) and overall $\mathrm{VO}_{2} \max$ $(\mathrm{R}=0.83)$ demonstrating the relationship between aerobic adaptations in muscle and improvements in performance with training (Tyler et al., 1998).

Many studies have shown that both endurance and high intensity training results in altered fibre type proportions in muscle, with the predominant effect being an increase in the oxidative capacity of Type II or fast twitch muscle fibres, resulting in an increased Type IIA/2A:Type IIB/2X ratio (Rivero, 2008; Valberg, 2014). Following 18 weeks of low intensity endurance training, there have even been increases in Type I:II fibre type ratios (Serrano et al., 2000). These changes are clearly beneficial to the aerobic capacity of the horse, but theoretically this transition results in a slower velocity of shortening overall (Rome et al., 1990) which may seem detrimental to speed and acceleration. However, even following the most intense exercise $\left(100 \%-110 \% \mathrm{VO}_{2 \max }\right.$ interval training on a treadmill for 32 weeks) there was a significant increase in the ratio of Type IIA to IIB muscle fibres (Tyler et al., 1998). It appears that the overriding adaption in muscle is in improvement in aerobic capacity, even if at the expense of overall muscle power, however, the differences in the velocity of shortening between Type IIA and IIX fibres in the horse has not been well studied for different muscles.

Increases in muscle capillary density, aerobic muscle enzymes and mitochondrial enzymes all occur relatively quickly in a training programme (by 7 weeks), compared the changes in either the contractile properties or size (16 weeks), however, no further adaptations after 16 weeks were observed except for mitochondrial volume and $\mathrm{VO}_{2 \max }$ (McGowan et al., 2002; Tyler et al., 1998). Knowledge of the time frame of these adaptions can be very useful when designing training programmes.

\section{Principles of specific training for performance}

In a sport horse, dysfunctions of neuromotor control may manifest themselves as poor technical performance or possibly as repetitive micro trauma or re-occurring overt muscle tension due to poor coordination. Therefore, identification of these dysfunctions using clinical reasoning processes and specific training to correct or prevent them is a vital part of training the equine athlete. Although there are few peer-reviewed publications on equine neuromotor training, knowledge from human research should be taken into consideration whilst training horses. For example, the three factors affecting motor control; the individual, the task and the environment, are as applicable to the horse as they are to humans. Other examples of applicable common components of movement are the perception, the cognition and the action (Shumway-Cook and Woollacott, 2012). Decisions made when planning a training programme for motor control should be based on knowledge of learning, motor control and skill development, as well as on the knowledge of the physiology of the tissues being trained. Types of exercises and tasks presented to the horse, repetition amounts, duration of exercises, amount of rest in relation to training etc. should all be justifiable through systematic application of this knowledge.

\section{Practice and learning}

For training to be purposeful, it needs to yield learning. Learning is considered to be a permanent change, involving acquisition of knowledge as basis for it, as well as memory as a result of it (Kandel, 2000). Motor learning has been defined by Shumway-Cook and Woollacott (2012) as 'the process of acquisition and/or modification of movement'. To optimise effectiveness of training, specificity is of importance. Therefore, the problems and weaknesses of the horse should be carefully identified, so that appropriate and targeted training can then take place. Motor skill is the outcome of learning: the effortless automaticity in movement.

Whenever training is commenced, the concept of the logarithmic law of practice should be remembered. The law states that most and fastest learning, and thus greatest improvement in performance, happens at the beginning of the practice period (Newell and Rosenbloom, 1982). Along with the amount of training increments, the improvement gradually slows down. This ties in together with the above- 
mentioned timing of muscle's physiological adaptions as response to training.

There are some basic factors of practical training that are utilised in humans in both training for rehabilitation as well as training for sports. These factors are thoroughly discussed, for example, in Shumway-Cook and Woollacott's (2012) text book, including elements such as massed practice or the distributed practice approach. Massed practice involves more practice than rest during the session, thus possibly leading to fatigue and possibly increasing the risk of injury. Distributed practice, in turn, has at least same amount or more time for rest than practice during a training session. Further aspects to consider are whether to do constant or variable practice: training with minimal or several variations in conditions, respectively. Within the latter, one can choose to do blocked, serial or random training. In humans the effect of different ways of practicing, and the related neurophysiology has been studied during the past ten years, and clear differences in the brain function during learning and in the result of learning have been seen (Lage et al., 2015).

Guidance and discovery are different methods of learning too. Movement in the case of a sport horse is often quite predominantly physically guided, by the rider's aids and the equipment used, as well as by the environment where the horse moves. The level to which discovery (horse practicing under unguided conditions) can be used as part of sports horse training, is questionable. Nevertheless, the options of whole versus part training are, again, applicable to the horse. The latter gives us a possibility to aim towards more specific training programmes where the dysfunction has been identified carefully, by breaking the task into pieces rather than training it as a whole. For example approach, push off, flight position, and landing in show jumping could be trained as individual parts of the task rather than just 'jump' as one big sum of the parts. The aim and purpose of practice and the task at hand dictates the exercise type selection.

As well as the aspects of learning and practice discussed above, the environment plays an important part in training especially with the sporting horse. A skill needs to be effectively transferred from one environment to another, which should be taken into account during practice. The factors of environment affecting the skill are, for example, the different surfaces, equipment, temperature, voices, strange horses and other variables that may change between training environment and competition environment. Moreover, the rider's effect should be considered as part of environment in which the horse has to perform in. The skill of the rider, and changes affecting that, may indirectly affect the horse too. An example could be the effect of audience, which seems to be bigger to the rider than to the horse, when they both are exposed to the same environment after equal training (Von Lewinski et al., 2013).

\section{Motor learning}

Motor learning is a physiological process. Resulting from a sufficient amount of stimulus, there will be structural changes at the cellular level. Examples of these would be habituation and sensitisation (implicit, procedural learning) related decreased strength of the synaptic connections between interneurons and motor neurons, and increased defence reflexes (Kandel, 2000). The use of these methods of learning have been reported in horses, but only from the point of view of behaviour, for example fearful situations and learning to cope with them (Christensen et al., 2006), rather than the point of view of movement or motor control. Nevertheless, one cannot separate motor learning from other, i.e. behavioural, aspects of learning, when training a horse. For example the attention span of a horse should be considered, which might also be affected by the age of the horse (Rapin et al., 2007), and the effects of individual's temperament as well as stresses in the learning situation should also be taken into account (Valenchon et al., 2013b).

\section{Conditional learning}

Conditional learning (also a version of implicit, procedural learning) in its classical form is about predicting relationship of one stimulus to another, and in its operant form is about predicting relationship of one's behaviour to a consequence (Shumway-Cook and Woollacott, 2012). In horses these methods have again previously been reported as part of behaviour directed research; especially the operant conditioning is widely discussed (Brubacker and Udell, 2016; Padalino et al., 2016; Starling et al., 2013; Valenchon et al., 2013a). However, it seems reasonable to also apply these methods to the motor learning and training processes for performance of athletic skills. As one learns, one's brain adapts to the function, and learns to predict things. This has been reported in several animal studies, the most famous example being Pavlov's dogs (Pavlov and Andrep, 2003). A noteworthy point is that as these methods are related to the physiological activity in tissues via, for example, the action potential, the timing of stimuli during training is critical (Kandel, 2000).

\section{Procedural learning}

In procedural learning one learns to perform tasks automatically, without attention or conscious thought. Changes in synaptic efficiency between neurons (climbing fibres, mossy fibres and Purkinje cells) in the cerebellum occur, to enable modification of movements (Yang and Lisberger, 2014). Procedural learning can be argued to represent, by essence, the nature of horses' movement. Horses have been reported to use procedural learning in, for 
example, matching to sample tests, where Shetland Ponies were tested for their ability to discriminate between different geometric symbols (Gabor and Gerkenemail, 2010).

\section{Application of learning theory}

Various parts of the brain work differently during different phases of learning. During the learning process, adaptation in certain parts of brain happens in relation to different functions at different phases of learning (Floyer-Lea and Matthews, 2004; Lage et al., 2015). Reduction in brain activity in several regions of brain can be seen in comparison to the learning phase (Floyer-Lea and Matthews, 2004). In humans age also has an effect on motor learning: old people need to practice more than young to achieve a skill, and their brain activity is still higher even when the skill is accomplished (Wu et al., 2005). Despite the obvious differences in the neurological (pyramidal) system between the species, and the fact that the cerebral cortex is less important in generating voluntary movements in a horse than in people (King, 1987), the above discussed principals of learning can be applied to training of horses, as learning is a complex process involving more than just the local musculoskeletal tissue.

An important basis for efficient and controlled movement to protect from tissue overload is postural control. Training core muscles in horses and use of dynamic mobilisation exercises has recently been reviewed (Clayton, 2016), although more specific research is warranted. Nevertheless, studies regarding the anatomy and the muscle fibre type distribution in various muscles in horses' gives preliminary information about the subject in horses (Hyytiäinen et al., 2014; Stubbs et al. 2006). However, training for postural control or core stability is well reported in humans (Massion, 1994; Peterka, 2002; O'Sullivan et al., 2014).

Skill training also acquires sufficient physical fitness level, strength and endurance as well as mobility, so that the horse can actually perform the tasks and repetition amounts required from it, with high quality and low risk. The horse should be healthy and pain free. Moreover, as communication is of importance, the owners/riders capability to communicate with their horse should be evaluated: are they capable of delivering the planned exercises and training to their horse appropriately, and also to interpret the outcome of the exercises correctly. Currently there are no validated outcome measures for evaluating equine motor learning. Any measures used should be task related and functional, in order to reflect the true nature of motor control and level of it.

\section{Practical muscle training}

Training of muscles is not based on pre-set recipes or some simple repeatable rules. In practical muscle training several factors, in addition to the motor control and its development, set the guidelines to what type of exercises could - and should - be done. In addition to the available knowledge, clinical reasoning and decision-making processes are required. Again, specificity is called for; rather than training with generic programmes, it might be more beneficial to define the specific muscle or muscle groups that need to be trained, and concentrate on them.

The anatomy and architecture of the muscle will define the direction of the movement according to the muscle's function; for example the mainly sagittal plane of hind limb flexion and extension when training $\mathrm{m}$. biceps femoris (Budras et al., 2003), or combined rotational and lateral flexion movements of the vertebrae when training $\mathrm{mm}$. multifidii (Stubbs et al., 2006). Anatomy and architecture also affects the range of movement of the exercise: large movements of several large joints (hip, stifle and tarsal joints) when wanting to affect the m. biceps femoris, and small, multidirectional movements of the spine when wanting to affect the $\mathrm{mm}$. multifidii.

Types of muscle work are also important factors. For example $\mathrm{m}$. biceps femoris works concentrically during hip and stifle extensions, abduction of the hip, and with its caudal part during flexion of the stifle and extension of the tarsus. During the opposite movements, working as an antagonist, it does eccentric work (Budras et al., 2003). The movements that are selected as exercises, and the various phases of these movements should be designed so that these components are emphasised according to the aim of the exercise. Information regarding muscle activation is of high importance; electromyographic studies of activation of some equine muscles have been published (Licka et al., 2009; Takahashi et al., 2014; Zsoldos et al., 2010), providing important information that allows for specific exercises to be performed. Muscle fibre type of a muscle does not only determine the repetition speed and amount, but also provides information regarding other properties and functions of the muscle. High type I fibre content has been reported to relate to high muscle spindle ratio (Botterman et al., 1978; Meyers and Hermanson 2006). Thus, mm. multifidii has a role to play in both postural control and motor control, in addition to its commonly considered function as spinal rotator and lateral flexor (Budras et al., 2003; Stubbs et al., 2006).

Ideally, outcome measures should be used, to quantify the effect of training. Although the tools are yet scarce, for $\mathrm{mm}$. multifidii the use of ultrasound for measuring the cross sectional area has been reported (Stubbs et al., 2010), and 
using that, the clear effects of a training regimen on that specific muscle have also been reported (Stubbs et al., 2011).

\section{Conclusions}

Athletic performance is ultimately the result of the actions of muscles. Muscular actions differ depending on the muscle group involved with anatomical and functional properties depending on the primary roles of the muscle; from stabilisation to powering locomotion. The functional (contractile and metabolic) properties of a muscle are determined by its fibre type or relative fibre type proportions in the muscle. The actions of muscle require the coordination of the nervous system with muscle contraction to produce movement or resist movement to avoid unwanted motion and tissue damage. The coordination of muscular action with the nervous system is termed neuromotor control and it requires precise proprioceptive input from the periphery, processing and input from the central nervous system (including learned or trained movements) and involves timing of muscle recruitment as well as muscle contraction.

Training of muscles involves training for strength and stamina with measureable physiological changes with training including increased fibre size, alterations in fibre type, alterations in glycogen concentrations and lactate transport and alterations in mitochondrial and capillary density. As well as standard athletic training, skills training can make the difference in athletic performance and injury prevention in the equine athlete. This involves training of neuromotor control; training motor skills by selection of the various specific practice approaches and focusing on selected forms of learning. Muscle training should rely on clinical reasoning processes based on the anatomy, architecture, physiology and function of a specific muscle. These practical specific training techniques can be used in injury prevention, rehabilitation post injury and maintenance of the athlete.

\section{References}

Bin Zayed Al Nahyan, H.H. Sheikh Sultan, 2016. The Boudheib initiative, World Horse Welfare Conference, London, UK, 2016. Available at: www.worldhorsewelfare.org/conference.

Botterman, B.R., Binder, M.D. and Stuart, D.G., 1978. Functional anatomy of the association between motor units and muscle receptors. American Zoologist 18: 135-152.

Brubaker, L. and Udell, M.A.R., 2016. Cognition and learning in horses (Equus caballus): what we know and why we should ask more. Behavioural Processes 126: 121-131.

Budras, K.-D., Sack, W.O. and Röck, S., 2003. Anatomy of the horse, $4^{\text {th }}$ edition. Schlütersche Verlag, Hannover, Germany.

Christensen, J.W., Rundgren, M. and Olsson, K., 2006. Training methods for horses: habituation to a frightening stimulus. Equine Veterinary Journal 38: 439-443.
Clayton, H.M., 2016. Core training and rehabilitation in horses. Veterinary Clinics of North America: Equine Practice 32: 49-71.

Crook, T.C., Cruickshank, S.E., McGowan, C.M., Stubbs, N., Wakeling, J.M., Wilson, A.M. and Payne, R.C., 2008. Comparative anatomy and muscle architecture of selected hind limb muscles in the Quarter Horse and Arab. Journal of Anatomy 212: 144-152.

Crook, T.C., Cruickshank, S.E., McGowan, C.M., Stubbs, N., Wilson, A.M., Hodson-Tole, E. and Payne, R.C., 2010. A comparison of the moment arms of pelvic limb muscles in horses bred for acceleration (Quarter Horse) and endurance (Arab). Journal of Anatomy 217: 26-37.

D’Angelis, F.H.F., Ferraz, G.C., Boleli, I.C., Lacerda-Neto, J.C. and Queiroz-Neto, A., 2005. Aerobic training, but not creatine supplementation, alters the gluteus medius muscle. Journal of Animal Science 83: 579-585.

Davie, A.J., Evans, D.L., Hodgson, D.R. and Rose, R.J., 1994. The effects of an oral glucose polymer on muscle glycogen resynthesis in Standardbred horses. Journal of Nutrition 124: 2740 S.

Floyer-Lea, A. and Matthews, P.M., 2004. Changing brain networks for visuomotor control with increased movement automaticity. Journal of Neurophysiology 92: 2405-2412.

Gabor, V. and Gerkenemail, M., 2010. Horses use procedural learning rather than conceptual learning to solve matching to sample. Applied Animal Behaviour Science 126: 119-124.

Gansen, S., Lindner, A., Marx, S., Mosen, H. and Sallmann, H.P., 1999. Effects of conditioning horses with lactate-guided exercise on muscle glycogen content. Equine Veterinary Journal. Supplement: 329-331.

Geor, R.J., McCutcheon, L.J. and Shen, H., 1999. Muscular and metabolic responses to moderate-intensity short-term training. Equine Veterinary Journal, Suppl. 30: 311-317.

Goff, L.M., Jeffcott, L.B., Jasiewicz, J. and McGowan, C.M., 2008. Structural and biomechanical aspects of equine sacroiliac joint function and their relationship to clinical disease. Veterinary Journal 176: 281-293.

Grenier, S.G. and McGill, S.M., 2007. Quantification of lumbar stability by using 2 different abdominal activation strategies. Archives of Physical Medicine and Rehabilitation 88: 54-62.

Gunn, H.M., 1987. Muscle, bone and fat proportions and muscle distribution of Thoroughbreds and other horses. In: Gillespie, J.R. and Robinson, N.E. (eds.) Equine exercise physiology 2. ICEEP Publications, Davis, CA, USA, pp. 253-264.

Hides, J.A., Jull, G.A. and Richardson, C.A., 2001. Long-term effects of specific stabilizing exercises for first-episode low back pain. Spine 26: E243-E248.

Hides, J.A., Richardson, C.A. and Jull, G.A., 1996. Multifidus muscle recovery is not automatic following resolution of acute first episode low level pain. Spine 21: 2763-2769.

Hodges, P.W., 2001. Changes in motor planning of feedforward postural responses of the trunk muscles in low back pain. Experimental Brain Research 141: 261-266.

Hodges, P.W., 2004. Motor control of the trunk. In: Boyling, J. and Jull, G. (eds.) Grieves' modern manual therapy of the vertebral column, $3^{\text {rd }}$ edition. Elsevier, Edinburgh, UK, pp. 119-139. 
Hodges, P.W. and Richardson, C.A., 1996. Inefficient muscular stabilization of the lumbar spine associated with low back pain. A motor control evaluation of transversus abdominis. Spine 21: 2640-2650.

Hodges, P.W. and Richardson, C.A., 1999. Altered trunk muscle recruitment in people with low back pain with upper limb movement at different speeds. Archives of Physical Medicine and Rehabilitation 80: 1005-1012.

Hodges, P.W., McGill, S. and Hides, J.A., 2013. Motor control of the spine and changes in pain: debate about the extrapolation from research observations of motor control strategies to effective treatments for back pain. In: Hodges, P.W., Cholewicki, J. and Van Dieën, J.H. (eds.) Spinal control. Churchill Livingstone-Elsevier, Edinburgh, UK, pp. 231-239.

Hodgson, D.R. and Foreman, J.H., 2014 Comparative aspects of exercise physiology. In: Hodgson, D.R., McKeever, K.H. and McGowan C.M. (eds.) The athletic horse: principles and practice of equine sports medicine, $2^{\text {nd }}$ edition. Elsevier, St Louis, MO, USA, pp. 9-18.

Hodgson, D.R. and McGowan, C.M., 2014. An overview of performance and sports medicine. In: Hodgson, D.R., McKeever, K.H. and McGowan, C.M. (eds.) The athletic horse: principles and practice of equine sports medicine, $2^{\text {nd }}$ edition. Elsevier, St Louis, MO, USA, pp. 1-8.

Hyytiäinen, H.K., Mykkänen, A.K., Hielm-Björkman, A.K., Stubbs, N.C. and McGowan, C.M., 2014. Muscle fibre type distribution of the thoracolumbar and hindlimb regions of horses: relating fibre type and functional role. Acta Veterinaria Scandinavica 27: 8.

Kandel, E.R., 2000. Cellular mechanisms of learning and the biological basis of individuality. In: Kandel, E.R., Schwartz, J.H. and Jessell, T.M. (eds.) Principles of neural science, $4^{\text {th }}$ edition. McGraw-Hill, New York, NY, USA, pp. 1247-1297.

Kawai, M., Minami, Y., Sayama, Y., Kuwano, A., Hiraga, A. and Miyata, H., 2009. Muscle fiber population and biochemical properties of whole body muscles in Thoroughbred horses. Anatomical Record 292: 1663-1669.

King, A.S., 1987. Physiological and clinical anatomy of the domestic mammals, Vol. 1, Central nervous system. Reprint in 2008, Blackwell Science Ltd, Oxford, UK.

Knechtle, B., Rüst, C.A., Rosemann, T. and Lepers, R., 2012. Agerelated changes in 100-km ultra-marathon running performance. Age 34: 1033-1045

Koho, N.M., Hyyppä, S. and Pösö, A.R., 2006. Monocarboxylate transporters (MCT) as lactate carriers in equine muscle and red blood cells. Equine Veterinary Journal, Suppl. 36: 354-358.

Lage, G.M., Ugrinowitsch, H., Apolinário-Souza, T., Mário Vieira, M., Albuquerque, M.R., Benda, R.N., 2015. Repetition and variation in motor practice: a review of neural correlates. Neuroscience and Biobehavioral Reviews 57: 132-141.

Licka, T., Frey, A. and Peham, C., 2009. Elecromyographic activity of the longissimus dorsi muscles in horses when walking on a treadmill. Veterinary Journal 48: 234-239.

MacDonald, D.A., Moseley G.L. and Hodges, P.W., 2006. The lumbar multifidus: does the evidence support clinical beliefs? Manual Therapy 11: 254-263.
MacDonald, D., Moseley, G.L. and Hodges, P.W., 2009. Why do some patients keep hurting their back? Evidence of ongoing back muscle dysfunction during remission from recurrent back pain. Pain 142: 183-188.

Massion, J., 1994. Postural control system. Current Opinion in Neurobiology 4: 877-887.

McGowan, C.M., Golland, L.C., Evans, D.L., Hodgson, D.R. and Rose, R.J., 2002. Effects of prolonged training, overtraining and detraining on skeletal muscle metabolites and enzymes. Equine Veterinary Journal, Suppl. 34: 257-263.

Meyers, R.A. and Hermanson, J.W., 2006. Horse soleus muscle: postural sensor or vestigial structure? Anatomical Record 228A: 1068-1076.

Neuman, D.A., 2010. Kinesiology of the musculoskeletal system. Foundations for rehabilitation, $2^{\text {nd }}$ edition. Mosby Elsevier, MI, USA.

Newell, A. and Rosenbloom, P.S., 1982. Mechanisms of skill acquisition and the law of practice. In: Anderson, J.R. (ed.) Cognitive skills and their acquisition. Erlbaum, Hillsdale, NJ, USA, pp. 1-55.

O'Sullivan, P.B., Phyty, G.D., Twomey, L.T. and Allison, G.T., 1997. Evaluation of specific stabilizing exercise in the treatment of chronic low back pain with radiologic diagnosis of spondylolysis or spondylolisthesis. Spine 22: 2959-2967.

O’Sullivan, S.B., Schmitz, T.J. and Fulk, G.D., 2014. Physical Rehabilitation, $6^{\text {th }}$ edition. FA Davis, Philadelphia, PA, USA.

Padalino, B., Henshall, C., Raidal, S.L, Knight, P., Celi, P., Jeffcott, L. and Muscatello G., 2016. Investigations into equine transport-related problem behaviours: survey results. Journal of Equine Veterinary Science 48: 166-173.

Panjabi, M.M., 1992a. The stabilizing system of the spine. Part I. Function, dysfunction, adaptation, and enhancement. Journal of Spinal Disorders 5: 383-389; discussion 397.

Panjabi, M.M., 1992b. The stabilizing system of the spine. Part II. Neutral zone and instability hypothesis. Journal of Spinal Disorders 5: 390-396; discussion 397.

Pavlov, I.P. and Anrep, G.V., 2003. Conditioned reflexes. Reprint of Courier Corporation, North Chelmsford, MA, USA.

Peterka, R.J., 2002. Sensorimotor integration in human postural control. Journal of Neurophysiology 88: 1097-1118.

Rapin, V., Poncet, P.A., Burger, D., Mermod, C. and Richard, M.A., 2007. Measurement of the attention time in the horse. Schweizer Archiv für Tierheilkunde 149: 77-83.

Reeves, N.P., Cholewicki, J., Pearcy, M. and Parnianpour, M., 2013. How can models of motor control be useful for understanding low back pain? In: Hodges, P.W., Cholewicki, J. and Van Dieën, J.H. (eds.) Spinal control. Churchill Livingstone-Elsevier, London, UK, pp. 187-193.

Rivero, J.L., 2007. A scientific background for skeletal muscle conditioning in equine practice. Journal of Veterinary Medicine Series A 54: 321-332.

Rivero, J.L. and Piercy R.J., 2008. Muscle physiology: responses to exercise and training. In: Hinchcliff, K.W., Geor, R.J. and Kaneps, A.J. (eds.) Equine exercise physiology: the science of exercise in the athletic horse. Saunders/Elsevier, Edinburgh, UK, pp. 30-80.

Rome, L.C., Sosnicki, A.A. and Goble, D.O., 1990. Maximum velocity of shortening of three fibre types from horse soleus muscle: implications for scaling with body size. Journal of Physiology 431: 173-185. 
Schiaffino, S. and Reggiani, C., 2011. Fiber types in mammalian skeletal muscles. Physiological Reviews 91: 1447-1531.

Serrano, A.L., Quiroz-Rothe, E. and Rivero, J.L., 2000. Early and longterm changes of equine skeletal muscle in response to endurance training and detraining. Pflügers Archiv 441: 263-274.

Starling, M.J., Branson, N., Cody, D., McGreevy, P.D., 2013. Conceptualising the impact of arousal and affective state on training outcomes of operant conditioning. Animals 3: 300-317.

Shumway-Cook, A. and Woollacott, M., 2012. Motor control, $4^{\text {th }}$ edition. Lippknott Williams and Wilkins, Philadelphia, PA, USA.

Stubbs, N.C., Hodges, P.W., Jeffcott, L.B., Cowin, G., Hodgson, D.R. and McGowan, C.M., 2006. Functional anatomy of the caudal thoracolumbar and lumbosacral spine in the horse. Equine Veterinary Journal, Suppl. 36: 393-399.

Stubbs, N.C., Riggs, C.M., Hodges, P.W., Jeffcott, L.B., Hodgson, D.R., Clayton, H.M. and McGowan, C.M., 2010. Osseous spinal pathology and epaxial muscle ultrasonography in Thoroughbred racehorses. Equine Veterinary Journal, Suppl. 38: 654-661.

Stubbs, N.C., Kaiser, L.J., Hauptman, J. and Clayton, H.M., 2011. Dynamic mobilisation exercises increase cross sectional area of musculus multifidus. Equine Veterinary Journal 43: 522-529.

Takashi, T., Matsui, A., Mukai, K., Ohmura, H., Hiraga, A. and Aida, H., 2014. The effects of inclination (up and down) of the treadmill on the electromyogram activities of the forelimb and hind limb muscles at a walk and a trot in Thoroughbred horses. Journal of Equine Science 25: 73-77.

Tyler, C.M., Golland, L.C., Evans, D.L., Hodgson, D.R. and Rose, R.J., 1998. Skeletal muscle adaptations to prolonged training, overtraining and detraining in horses. Pflügers Archiv 436: 391-397.
Valenchon, M., Lévy, F., Górecka-Bruzda, A., Calandreau, L. and Lansade, L., 2013a. Characterization of long-term memory, resistance to extinction, and influence of temperament during two instrumental tasks in horses. Animal Cognition 16: 1001-1006.

Valberg, S.J., 2014. Muscle anatomy, physiology and adaptations to exercise and training. In: Hodgson, D.R., McKeever, K.H. and McGowan, C.M. (eds.) The athletic horse: principles and practice of equine sports medicine, $2^{\text {nd }}$ edition. Elsevier, St Louis, MO, USA, pp. 174-201.

Valenchon, M., Lévy, F., Prunier, A., Moussu, C., Calandreau, L. and Lansade, L., 2013b. Stress modulates instrumental learning performances in horses (Equus caballus) in interaction with temperament. PLoS ONE 23: e62324.

Van Dieën, J.H. and Kingma, I., 2013. Spine function and low back pain: interactions of active and passive structures. In: Hodges, P.W., Cholewicki, J. Van Dieën, J.H. (eds.) Spinal control. Churchill Livingstone-Elsevier, London, UK, pp. 41-57.

Von Lewinski, M., Biau, S., Erber, R., Ille, N., Aurich, J., Faure, J.M., Mostl, E. and Aurich, C., 2013. Cortisol release, heart rate and heart rate variability in the horse and its rider: different responses to training and performance. Veterinary Journal 197: 229-232.

Wu, T. and Hallett, M., 2005. The influence of normal human ageing on automatic movements. Journal of Physiology 562: 605-615.

Yang, Y. and Lisberger, S.G., 2014. Purkinje-cell plasticity and cerebellar motor learning are graded by complex-spike duration. Nature 510: 529-532.

Zsoldos, R.R., Kotschwar, A., Kotschwar A.B., Rodriquez, C.P., Peham, C. and Licka, T., 2010. Activity of the equine rectus abdominis and oblique external abdominal muscles measured by surface EMG during walk and trot on the treadmill. Equine Veterinary Journal, Suppl. 38: 523-529. 